\title{
RELEVANCE OF STRATEGIC MANAGEMENT IN ICT BASED SMALL AND MEDIUM ENTERPRISES
}

*Note: Do not include the author(s) names and information as this document will be blind reviewed and they will be entered during proposal submission.

\section{ABSTRACT}

The focus of this research is to determine the relevance of strategic management process in performance of Information and communication technology (ICT) based small and medium enterprise (SME). For this purpose, an in-depth interview is conducted on a sample of twelve ICT based SMEs. The data collected from the interview are then analyzed by using different tools namely; Political, Economic, Social, and Technological (PEST) analysis, Porter's five forces analysis, Balanced Scorecard (BSC) and Analytic Hierarchy process (AHP).

The PEST analysis and five forces analysis gave an overview of the state of the ICT based industry. It was seen that the industry attractiveness of this sector was fairly high with only technological dynamism and bargaining power of clients being two most influential factors to affect the industry. For assessing the relevance of strategy in firm's performance two approaches; financial analysis and BSC analysis were used. Both the financial performance analysis and Balanced Scorecard performance evaluation method strongly indicated the positive influence of strategic management process in the performance of the ICT companies.

Finally, an integrated PEST, BSC and AHP approach was used to evaluate the performance of individual studied companies. Based on the measures drawn through PEST and BSC analysis criteria and sub criteria were derived and AHP was used to evaluate the performance of the companies. As the research output, a dynamic strategic management framework is presented as the recommendation for adopting strategic management process in ICT based SMEs. This study demonstrates the utility of an integrated AHP approach, which not only evaluates the performance of ICT based SMEs but also gives insight on the area of improvement for any individual company.

Keywords: AHP, BSC, PEST, SME, Strategic Management

\section{Introduction}

SMEs are considered to be the engine of economic growth through employment generation, contribution to gross domestic product (GDP), technological innovations and other aspects of economic and social development. ICT based enterprises are an integral part of the SME domain of Nepal. The development of ICT sector has positively influenced many other sectors including agriculture, banking, commerce, health care, education, publishing, transportation, etc. There are currently around five hundred registered ICT companies. There have been evidences of strategy influencing the performance of ICT companies. In context of Nepal, the impact and relevance of strategic 
management in SMEs is hugely unexplored, let alone in ICT based companies. Many researchers have stressed its importance in small and medium enterprises mainly in US and Europe, but the extent of its impact in the performance and sustainability of Nepalese ICT based SME sector needs to be investigated.

\section{Literature Review}

\subsection{Strategic Management and Performance of SMEs}

While there have been plenty of concrete findings for the use of strategy in big business houses, the nature of strategy and its effect in SMEs remain largely unexplored. SMEs are too busy dealing with operational problems and events on a day-to-day basis to devote time to strategic management (Hanlon \& Scott, 1993). Barring a few exceptions, small business managers do not value formal planning, strategic thinking and a long-term vision (Pelham, 2000). Therefore the nature of rigid planning trend in SMEs becomes highly questionable. According to (Gibcus \& Kemp, 2003), in their summarization of various researches conducted linking strategy to performance of SMEs, there seem to be some positive impact of strategy on the performance of a SME, though the results are not straight forward strategy seems to be an important variable. In context of this research it will be interesting to figure out what kind of impact does strategic management has in ICT based SMEs of Nepal.

\subsection{Performance Evaluation by AHP}

For the purpose of this research, the AHP is used as a method to evaluate performance and formulate a strategic framework based on the criteria derived from PEST and BSC analysis. The AHP approach enables us to assign weightage to each of the criteria and sub criteria. Many other methods for conducting this process can be undertaken. But AHP based approach is chosen because of its flexibility in data analysis, which allows us to perform various dynamic result analysis to draw appropriate conclusions.

Globally, there are few researchers who have integrated BSC and AHP for strategy formulation and performance analysis purposes. Erbasi \& Parlakkaya (2012) in their study have formulated a seven stage strategic process combining BSC and AHP for strategic management as well as performance evaluation of hotel industries. Similarly such practices have been detected in IT industry as well. Feili et al. (2011) have used BSC and AHP integrated approach for the performance evaluation of information technology in industry. Lee et al. (2008) aimed to construct an approach based on AHP and BSC for evaluating IT department in manufacturing industries in Taiwan by applying BSC to define hierarchy with four major perspectives, defining performance indicators for each perspective then finally using AHP approach to facilitate the solving process.

In our context, extensive use of BSC has been commenced, mainly for performance evaluation purposes. While AHP approach has been used by various sectors mainly for decision making purposes. Bhattarai (2014), in his study have observed the diffusion of AHP since 2003 and found its use in development decisions, academia and industry in Nepal. But the integrated approach of BSC and AHP for Strategy formulation seems novice. 


\section{Hypotheses/Objectives}

The specific objectives of this research are:

- To examine the state of industry environment of ICT based SMEs.

- To determine the relationship between strategic management process and performance the companies.

- To develop a strategic management framework suitable for ICT based SMEs.

\section{Research Design/Methodology}

Based on the theory of AHP several steps have been followed for the development of AHP framework, which are listed below:

- 12 ICT based SMEs were selected based on 2 criteria; first being, the company should be categorized as small or medium enterprise under the industrial act 1997, and second being, the company should be registered as ICT based company as per the registration act of Nepal, (2006 A.D).

- To explore in-depth insights and clarify concepts on strategic management practices, a detailed questionnaire was formulated and survey was carried out among top-level management of the respective companies through personal interview.

- PEST analysis and BSC evaluation was carried out on the data collected to draw out the relevant measures (sub criteria) for each of the steps (criteria) of strategic management process.

- A questionnaire based on pairwise comparison of different level of hierarchies was developed and data was collected from the respondents of the sampled companies for analysis.

\section{Data/Model Analysis}

A model was developed primarily based on the theory of strategic management. The four major steps of strategic management; Environmental analysis, Strategy formulation, Strategy Implementation, Control and evaluation, were considered as the primary criteria. The personal interview questionnaire was related to exploring the details and processes relating to these four criteria. Based on the detailed data analysis through PEST and BSC methods, the sub criteria were derived which were appropriate for ICT based SMEs of Nepal. Hence formulated AHP model is shown in Figure 1.

The response obtained through pairwise comparison of criteria and sub criteria with respect to the goal was aggregated by calculating geometric mean using Microsoft Excel 2010. The inconsistency ratio was found to be 0.04 which was lower than the threshold value of 0.1 . Finally pairwise comparative data was entered according to the interview conducted for alternatives with respect to the criteria and sub criteria using Expert Choice Software ver 4.47. The inconsistency ratio was found to be less than 0.1 . 


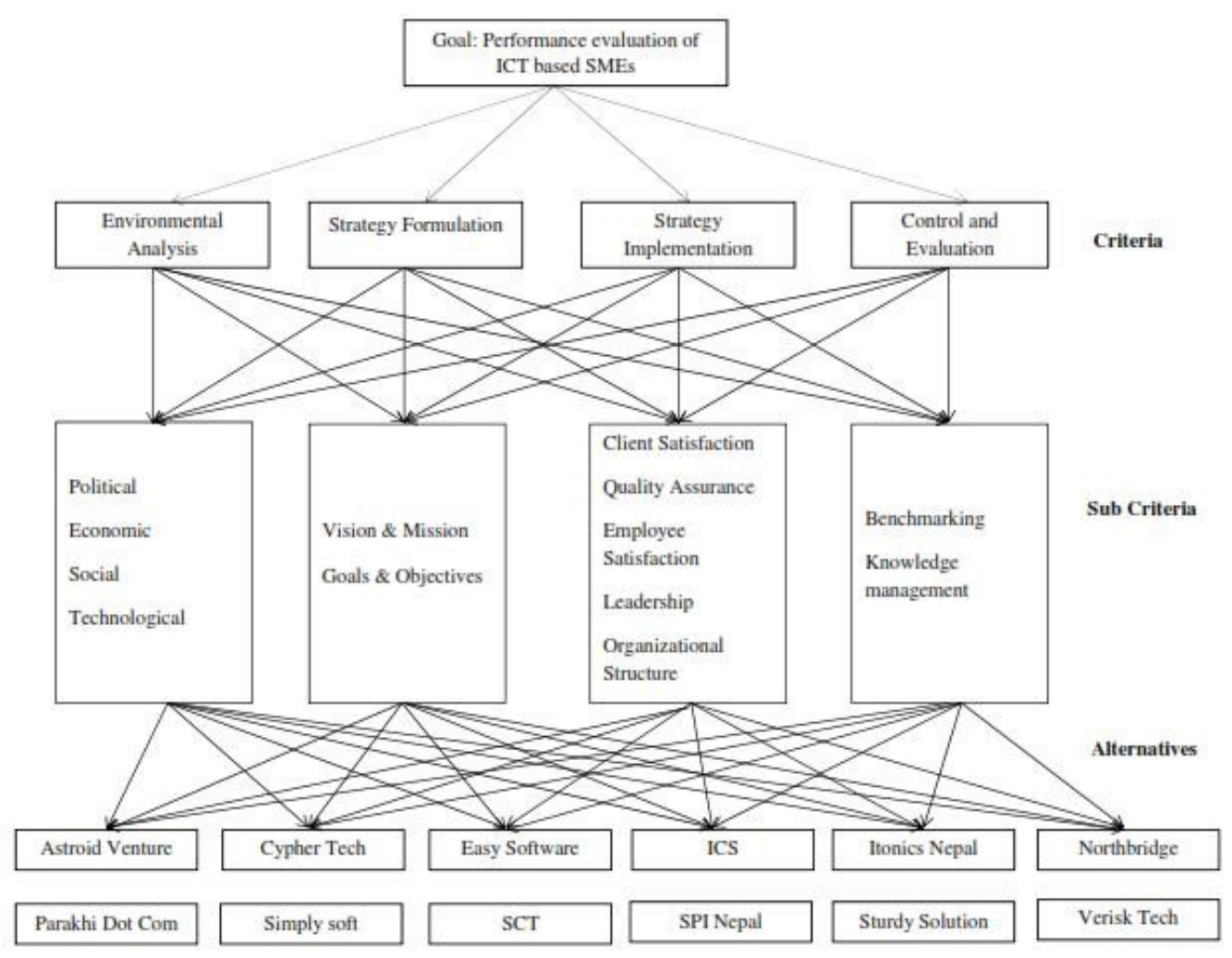

Figure 1: AHP model for performance evaluation of ICT based SMEs

\section{Limitations}

- The study has considered twelve ICT based small and medium enterprises; all centered in Nepal, hence generalization may or may not be appropriate.

- This research is predominantly based on the findings derived from the in-depth interviews conducted hence knowledge and judgement of the researcher may influence the study.

\section{Conclusions}

The ranking of the ICT based SMEs was done by prioritization of components of strategic management process which were derived using PEST and BSC analysis. SPI Nepal was ranked as the top performing company whereas Simply Soft was ranked in the bottom of the list. Further a sensitivity analysis shows the importance of Strategic implementation process and improvements to be undertaken in various steps of the implementation process to enhance the performance of low ranking companies. This research has added a literature to demonstrate the integrated use of AHP in Nepalese small and medium enterprises domain. The study not only ranks the studied companies but also gives insight on different steps of the strategic management process so as the companies could focus on improving their overall performance. Based on the AHP model and the dynamic sensitivity analysis feature of AHP software, a strategic management 
ISAHP Article: A Style Guide for Paper Proposals To Be Submitted to the International Symposium on the Analytic Hierarchy Process 2016, London, U.K.

framework most suitable for ICT based SMEs was formulated, which could add value to management and entrepreneurs.

\section{Key References}

Bhattarai, S. (2014). Difusion of Analytic Hierarchy Process in Nepal: Overview for the Period of 2003-2013. International Symposium of the Analytic Hierarchy Process (pp. 17-20). Washington D.C.: ISHAP 2014.

Erbasi, A., \& Parlakkaya, R. (2012). The Use of Analytic Hierarchy Process in the Balanced Scorecard: An Approach in a Hotel Firm. Business and Management Review, 2, 23-37.

Feili, H. R., Farahani, N. V., \& Vesaghi, N. (2011). Integration of Fuzzy Analytic Hierarchu Process (FHAP) with Balance Score Card (BSC) in order to Evaluate the Performance of Information Technology in Industry. The Journal of Mathematics and Computer Science, 2, 271-283.

Gibcus, P., \& Kemp, R. (2003). Strategy and small firm performance. SCientific AnaLysis of Entrepreneurship and SMEs (SCALES).

Hanlon, D., \& Scott, M. (1993). Strategy formation in the entrepreneurial small firm. Scottish Enterprise Foundation (SEF).

Lee, A. H., Chen, W.-C., \& Chang, C.-J. (2008). A fuzzy AHP and BSC Approach for Evaluating Performance of IT Department in the Manufacturing Industry in Taiwan. Expert Systems with Applications: An International Journal, 96-107.

Pelham, A. (2000). Market orientation and other potential influences on performance in small and medium-sized manufacturing firms. Journal of Small Business Management, 48-67.

Saaty, T. L. (1980). The Analytic Hierarchy Process. New York: McGraw-Hill. 